International Research Journal of Management, IT \& Social Sciences
Available online at https://sloap.org/journals/index.php/irjmis/
Vol. 6 No. 6, November 2019, pages: 178 187
ISSN: 2395-7492
https://doi.org/10.21744/irjmis.v6n6.794

\title{
The Brake Pressure Depends Upon the Pedal Ratio
}

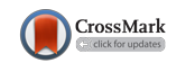

\author{
Julia Sophie Lotte ${ }^{\text {a }}$ \\ Daan Sem Luuk ${ }^{\text {b }}$ \\ Sven Noah Max ${ }^{\mathrm{c}}$ \\ Alexander Simon Nick ${ }^{\mathrm{d}}$
}

Article history:

Received: 27 July 2019

Accepted: 30 September 2019

Published: 05 November 2019

\author{
Keywords: \\ master cylinder; \\ pedal; \\ proper pedal; \\ ratio; \\ vehicle;
}

\begin{abstract}
The brake disc having a factor of safety (FOS) within the range of 2 to 3 is sustainable. The disc with a FOS less than 2 or greater than 3 undergoes distortion and are less sustainable. Theoretically it has been proven using graphs and calculations that a slight variation in the pedal ratio leads to a large variation in the clamping forces and stopping distance. As per the comparisons made from the FOS and as per result from Ansys, when the pedal force is $1200 \mathrm{~N}$ and the pedal ratios are 7.2and 4.5, the FOS are 2.1 and 2.8 respectively. Hence the disc is sustainable. When the pedal force is $1500 \mathrm{~N}$, and the pedal ratio is 4.5 , the FOS is 2.2 . Hence in this case too, the disc is sustainable. Therefore by maintaining proper pedal ratios, the length of the pedal can be made compact and with effective braking effects. This phenomenon is useful in case of racing vehicles as it reduces the effort of driver. The proper pedal design work also determines the size of master cylinder to be adopted for the vehicle.
\end{abstract}

2395-7492@ Copyright 2019. The Author. This is an open-access article under the CC BY-SA license (https://creativecommons.org/licenses/by-sa/4.0/) All rights reserved.

\section{Author correspondence:}

Julia Sophie Lotte,

University of Amsterdam, Amsterdam, Netherlands.

Email address: lotte@uva.nl

\section{Introduction}

A brake is a Mechanical element by means of which artificial frictional resistance is applied to the moving elements, in order to stop the motion of machine, the present work aims in optimizing the Brake performance by changing the Pedal ratios and applied Pedal force. In this paper, a Brake disc is designed in Solid works and the analysis of the disc is done in ANSYS by varying pedal ratios and pedal forces. Therefore the main aim of this paper, is to evaluate the brake performance by determining an optimum pedal ratio for easiness and flexibility of driver (Tretsiak et al., 2008).

\footnotetext{
${ }^{\text {a }}$ University of Amsterdam, Amsterdam, Netherlands

${ }^{\mathrm{b}}$ University of Amsterdam, Amsterdam, Netherlands

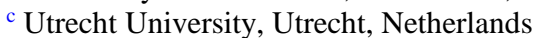

${ }^{\mathrm{d}}$ Utrecht University, Utrecht, Netherlands
} 
Generally Disc used in brake system is made of grey cast iron casting after proper design. Most of automobile shops will not respond for disc problems often they used to replace the brake system, this is done where the service cost is more than the replacement cost but as per mechanical design, Most of the brake discs are made of gray cast iron, so discs are damaged in one of three ways Scoring, cracking, Warping or excessive rusting and the type of forces acting on the brake disc (Van Winsum, 1999; Kim et al., 2008).

The deformation or any sorts of stress are developed on the disc after the application of the forces. There are two types of forces are acting on the brake pedal, the general tangential force is defined as the force which is acting on a moving body in the perpendicular direction to the motion of the body, with this effect the velocity may increase or decrease. Tangential force (T.F) is used to determine the stress developed in discs. The tangential force is the product of frictional coefficient and caliper force. Another force is clamping force which is defined as the force pressing each brake pad against the disc and is the product of brake pressure, area of caliper piston and number of pistons, the brake pressure is the ratio of the force on brake pedal and area of master cylinder. Different forces acting on a disc brake is shown in the figure1. The braking pressure is the of tangential friction force acting between the brake pads and disc, which is calculated by the product of force applied by driver and pedal ratio (Eriksson et al., 2002; El-Tayeb et al., 2009).

The Braking torque is the moment of braking force about the center of rotation, which is calculated by the product of tangential force and radius of disc. Another parameter is stopping distance which is the distance moved between the instant when rider decides to retard the vehicle moving, and the instant when the vehicle comes to rest. In general the stopping distance is depending on factors, like road condition i.e rough or smooth (coefficient of friction) and the the driving skills of the driver (Kamijo et al., 2007; Park et al., 2006).

As the work done by the brake is equal to the kinetic energy loosed by the vehicle during that time the heat dissipated to the surroundings all are equal, means the vehicle looses the kinetic energy and work done on the brake by equating the work done by the brake and lose of kinetic energy the stopping distance can be calculated

$$
\text { Tangential force } \times \text { Distance travelled }=\frac{1}{2} m v^{2}(\text { Kinetic energy })
$$

The factors which are responsible for brake performance are change in pedal ratio, change of driver applied force on the pedal, change in dimensions i.e., diameter of the disc brake, change in velocity of the vehicle, change in material properties. From these reasons we have considered the variations in the pedal ratio and relatively the changes in the driver applied force on pedal to determine the deformations occurring and thus the brake performance (Chargin $e t$ al., 1997; Barbarisi et al., 2009).
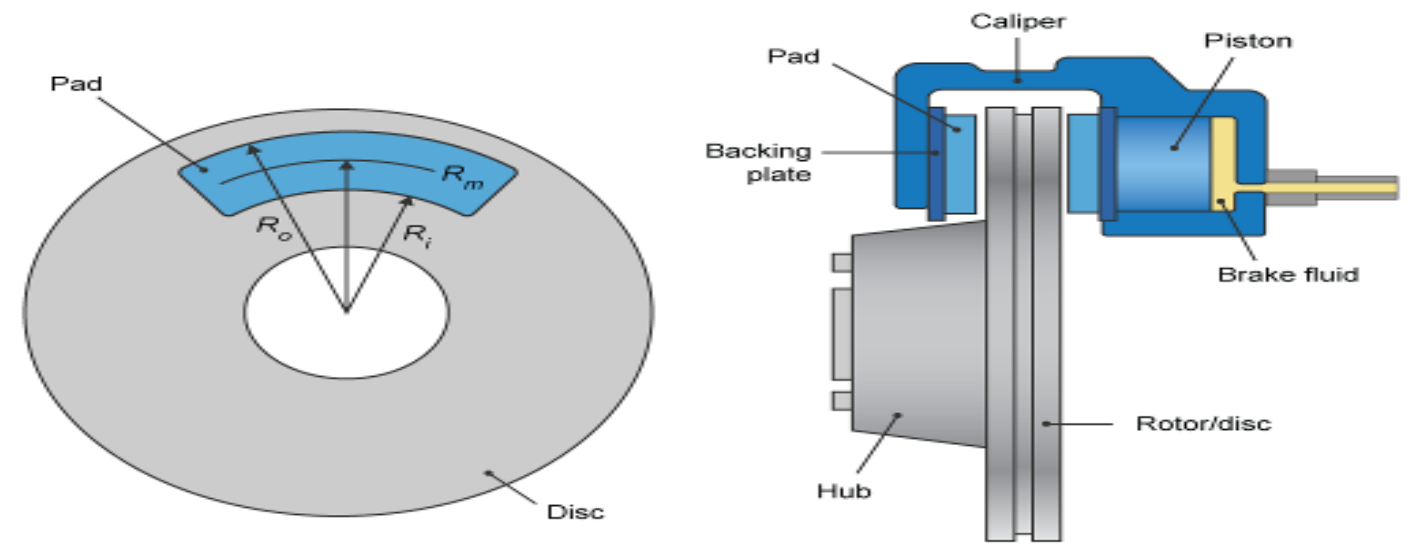

Figure 1. Forces acting on a braking system

Lotte, J. S., Luuk, D. S., Max, S. N., \& Nick, A. S. (2019). The brake pressure depends upon the pedal ratio. International Research Journal of Management, IT and Social Sciences, 6(6), 178-187. https://doi.org/10.21744/irjmis.v6n6.794 

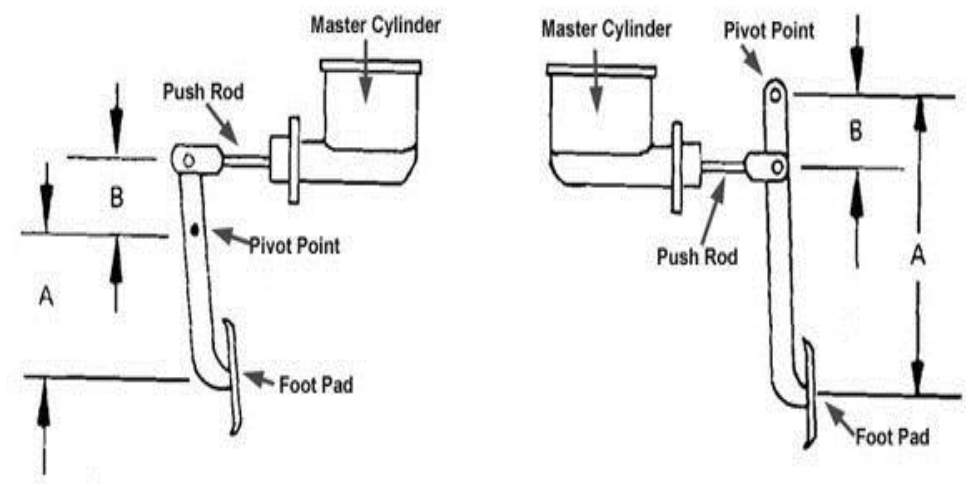

Figure 2. Different pedal alignments

\section{Materials and Methods}

In this work three different conditions are tested for go-kart vehicle based on the different leverage principles mainly first or second lever principles are adopted in designing the brake pedal. Brake pedal multiplies the force exerted by the driver on pedal. Brake pedal alignments are done based on first or second lever principles. Pedal ratio is the ratio of leverage your clutch pedal applies to the master cylinder (Bera et al., 2011; Kinkaid et al., 2003). To determine the pedal ratio you need to measure the height of the pedal to the pivot point then divided the measurement of the pivot point to the lower arm that controls your rod to the master cylinder. When a brake pedal gets modified to "fit" in a vehicle or a booster/master cylinder gets installed where it "fits" in the car, the pedal ratio is rarely taken into consideration. Proper pedal ratio is a must when installing and operating a brake system. Below in fig3 shows how to properly figure pedal ratio:

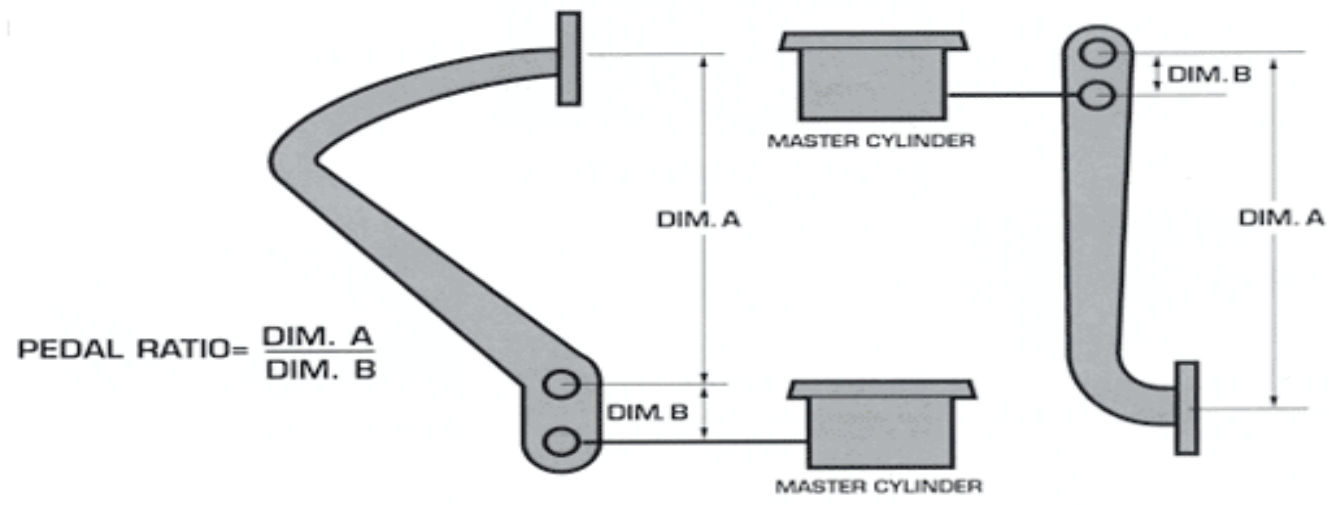

Figure 3. Brake pedal ratio

In a manual brake system, the pedal ratio will be between $5: 1$ and $6: 1$ and a power brake system it will be between 4:1 and 5:1. An excellent example is our Mustang kits for the 1967-1970 years. We include a brake pedal to adjust the ratio from the manual ratio to the desired power ratio. The new pedal raises the upper mounting pivot point about 2 $1 / 2$ ". If the correct pedal ratio is not achieved, the pedal will be extremely sensitive due to too much pressure being applied too quickly (Hui et al., 2010). 
3 Results and Discussions

When the brake pedal (or clutch pedal) is too hard to push, driving your car becomes not only difficult, but downright dangerous. Disc brake conversions are great, but even converting to a power-assist braking system can alter the feel of the brake pedal, and not all vehicles are capable of using power brakes, so ensuring that the pedal ratio is correct is paramount to practical and safe operation of the vehicle. This is a common theme for customized cars, one that is too often ignored.

A common misunderstanding with master cylinders is selecting the right one. The main issue with manual brake master cylinders is that the larger the cylinder bore, the harder it is to press. This is due to the fact that there is more fluid in front it. The rule of thumb for manual brakes is no larger than 1", with 7/8" being optimum for factory-type master cylinders. Power-assist master cylinders have a lot of help to move that piston, so they use a larger cylinder bore. Do not use a power master cylinder in a manual application.

The master cylinder bore size is a key component to getting functional brakes. Even with the correct master cylinder, the brake pedal ratio is the biggest factor in pedal effort. Pedal ratio difference in length between the pivot (fulcrum) of the pedal to the pushrod hole (Y) and the fulcrum to the center of the brake pedal (X). A power system should have a ratio between 4 and 5:1, where a manual system should be between 5 and 7:1. Master cylinder with a 1inch bore and a brake pedal ratio of $6: 1$ with 100 pounds of pedal pressure yields 600 pounds of pressure at the master cylinder. Cut that brake pedal ratio to $4: 1$, and the pressure at the master drops to just 400 pounds with the same effort, that is a significant difference.

In this work different cases are considered based on the literature and overall length $(\mathrm{A}+\mathrm{B})($ " $\mathrm{A}$ " represents distance between pivot to master cylinder and B indicates the distance between pivot rod to push rod as shown in fig 2) is considered as $18 \mathrm{~cm}$ as most of the go karts will use this pedal ratio.

The following parameters are considered for the pedal force calculation, these values are taken from the gokart system developed in our institution. The pedal force calculations are done by assuming no slip occurs in the brake and the frictional coefficient as 0.4 as the pedal contains rubber pad, with this anyone can alter the value of Frictional coefficient.

Table 1

Parameter value

\begin{tabular}{ll}
\hline Parameters & Values \\
\hline Frictional coefficient & 0.4 \\
Master cylinder diameter & $10 \mathrm{~mm}$ \\
Caliper piston diameter & $25.4 \mathrm{~mm}$ \\
No. of calipers used & 02 \\
Velocity & $45 \mathrm{~km} / \mathrm{hr}$ \\
Pedal length & $18 \mathrm{~cm}$ \\
\hline
\end{tabular}

Table 2

The total length of brake pedal

\begin{tabular}{llllll}
\hline Sno & $\begin{array}{l}\text { Total length of brake } \\
\text { pedal }(\mathrm{A}+\mathrm{B})\end{array}$ & $\begin{array}{l}\text { Length } \\
(\mathrm{A})\end{array}$ & $\begin{array}{l}\text { Length } \\
(\mathrm{B})\end{array}$ & $\begin{array}{l}\text { Pedal ratio } \\
(\mathrm{A}+\mathrm{B} / \mathrm{B})\end{array}$ & Pedal Force N \\
\hline 1 & 18 & 15.5 & 2.5 & 7.2 & 1042 \\
2 & 18 & 15 & 3 & 6.0 & 1200 \\
3 & 18 & 14.5 & 3.5 & 5.1 & 1345 \\
4 & 18 & 14 & 4 & 4.5 & 1500 \\
5 & 18 & 13.5 & 4.5 & 4.0 & 1658 \\
6 & 18 & 13 & 5 & 3.6 & 1810 \\
\hline
\end{tabular}

Lotte, J. S., Luuk, D. S., Max, S. N., \& Nick, A. S. (2019). The brake pressure depends upon the pedal ratio. International Research Journal of Management, IT and Social Sciences, 6(6), 178-187. https://doi.org/10.21744/irjmis.v6n6.794 
Table 3

The pedal ratio and pedal force

\begin{tabular}{llll}
\hline Sno & Pedal ratio & Pedal force & Driver applied force \\
\hline 1 & 7.2 & 1042 & 168.1 \\
2 & 6.0 & 1200 & 240.0 \\
3 & 5.1 & 1345 & 324.7 \\
4 & 4.5 & 1500 & 428.6 \\
5 & 4.0 & 1658 & 552.7 \\
6 & 3.6 & 1810 & 696.2 \\
\hline
\end{tabular}

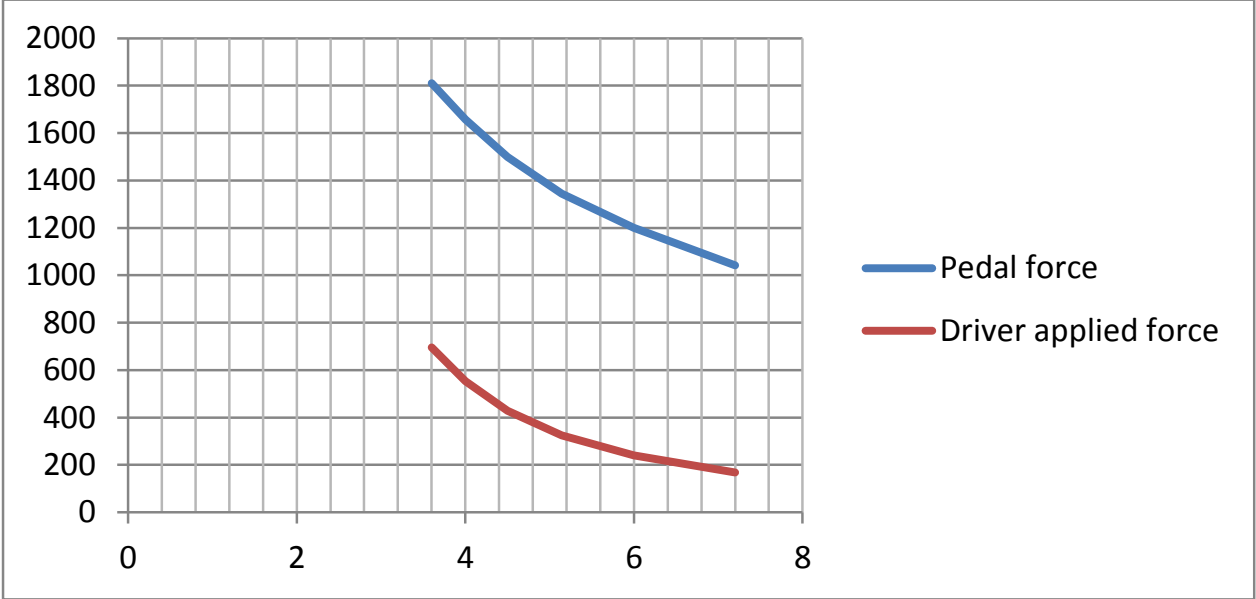

Graph 1. Variation of driver applied force with pedal force

From the above graphs it is clear that a slight variation in the pedal ratio resulted in large variation in the clamping forces and stopping distances A $200 \mathrm{~mm}$ diameter disc is used for the design and analysis of brakes performance. For the above mentioned diameter the deformations and stress conditions are determined. Along with dimensions the material properties are important to verify its performance. The material of disc being used is GREY CAST IRON Grey cast iron is the traditional material used for brake disc applications for the majority of the vehicles. Grey cast iron offers superior properties and advantages, and is more suited to brake disc manufacture when compared to other irons such as ductile (SG) iron and compacted graphite cast iron. The primary advantage of this grey cast iron is its high thermal conductivity, arising from continuous flake graphite structure, giving the brake disc the ability to dissipate heat efficiently, which is essential for the intended applications.

Table 4

Grey cast iron Disc material properties

\begin{tabular}{ll}
\hline Properties & Values \\
\hline Density & $7200 \mathrm{~kg} / \mathrm{m}^{3}$ \\
Young's Modulus & $110 \mathrm{Gpa}$ \\
Poisson's ratio & 0.28 \\
Thermal conductivity & $53.3-54$ \\
\hline
\end{tabular}

Based on the above theoretical conclusions and material properties, a brake disc has been designed for go-kart 


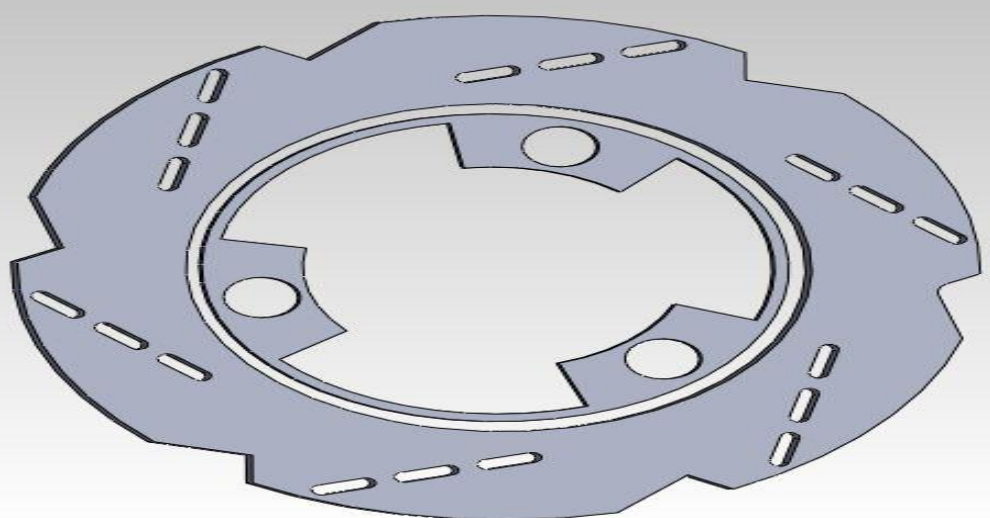

Figure 4. A brake disc

Final considerations which are made for the analysis of the disc Since the material used is grey cast iron, we have it's Material Properties and it's respective values as- Ultimate tensile strength of grey cast iron as 140-145Mpa and Yield Strength as $98-276 \mathrm{Mpa}$.

Factor Of Safety (FOS): In a static structural analysis, FOS value ranges between 2 to 3 . If the FOS value is below or above the range, the disc cannot sustain for the given pedal force and pedal ratio. The braking force which is obtained for different pedal ratios and pedal forces applied is tabulated as given below. The disc is analysed for the following pedal forces and pedal ratios based on that the tangential force is calculated.

Table 5

The values of braking force obtained by varying pedal ratios and pedal forces

\begin{tabular}{lll}
\hline Pedal Force & Pedal Ratio & Braking/Tangential Force \\
\hline $1200 \mathrm{~N}$ & 7.2 & $46175.89 \mathrm{~N}$ \\
$1200 \mathrm{~N}$ & 4.5 & $35996.72 \mathrm{~N}$ \\
$1200 \mathrm{~N}$ & 3.6 & $26336.06 \mathrm{~N}$ \\
$1500 \mathrm{~N}$ & 7.2 & $53996.123 \mathrm{~N}$ \\
$1500 \mathrm{~N}$ & 4.5 & $44996.04 \mathrm{~N}$ \\
$1500 \mathrm{~N}$ & 3.6 & $33747.84 \mathrm{~N}$ \\
\hline
\end{tabular}

Based on the above values and calculations, the results obtained in ANSYS are

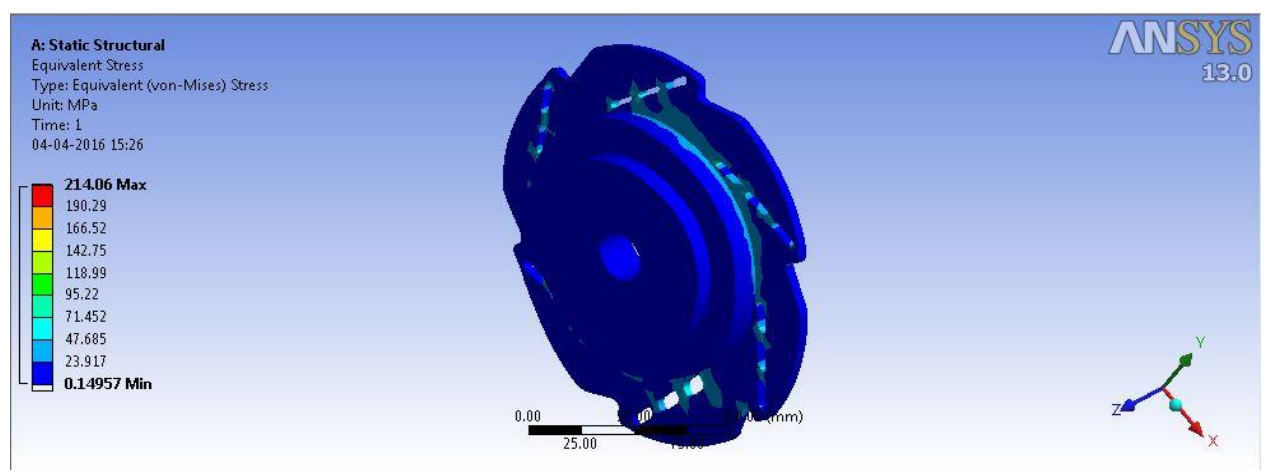

Case 1: Pedal force $=1200 N$, pedal ratio=6:1, Braking Force $=35996.72 \mathrm{~N} ; \mathrm{FOS}=2.1$

Lotte, J. S., Luuk, D. S., Max, S. N., \& Nick, A. S. (2019). The brake pressure depends upon the pedal ratio. International Research Journal of Management, IT and Social Sciences, 6(6), 178-187. https://doi.org/10.21744/irjmis.v6n6.794 


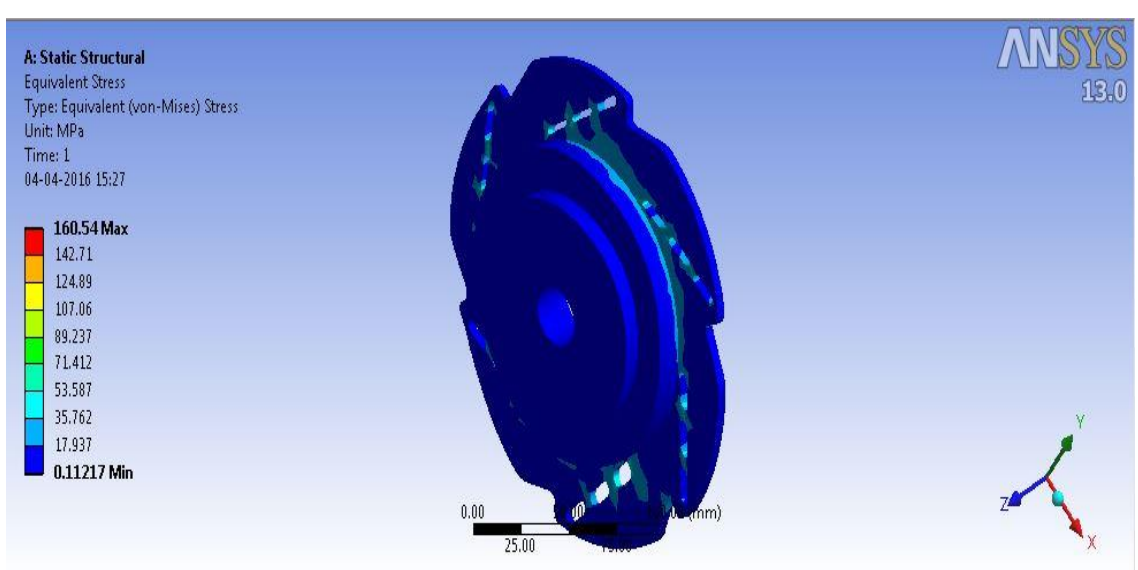

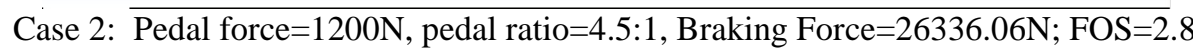

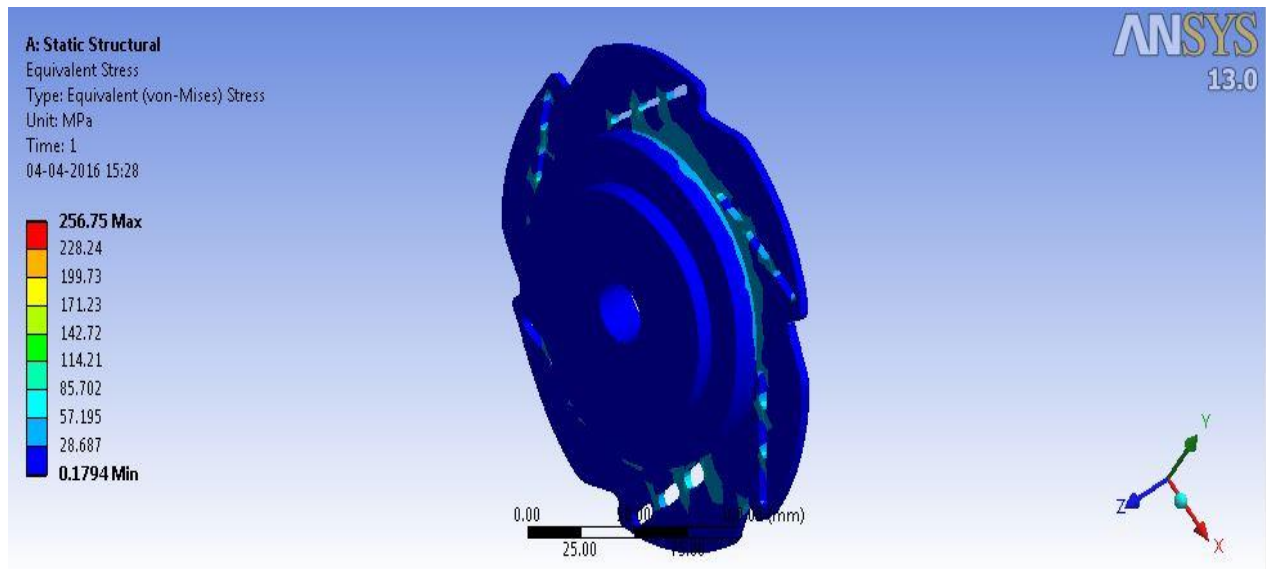

Case 3: Pedal force $=1200 \mathrm{~N}$, Pedal ratio $=4.5: 0.625$, Braking Force $=46175.89 \mathrm{~N} ; \mathrm{FOS}=1.75$

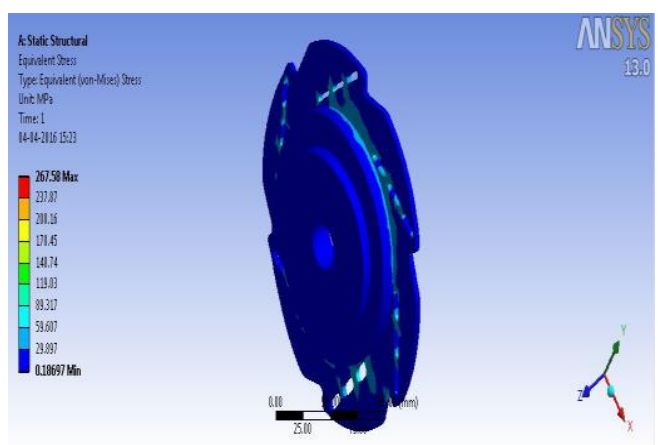

Case 4: Pedal force $=1500 \mathrm{~N}$, Pedal ratio=6:1, Braking Force=44996.04N; FOS=1.68 


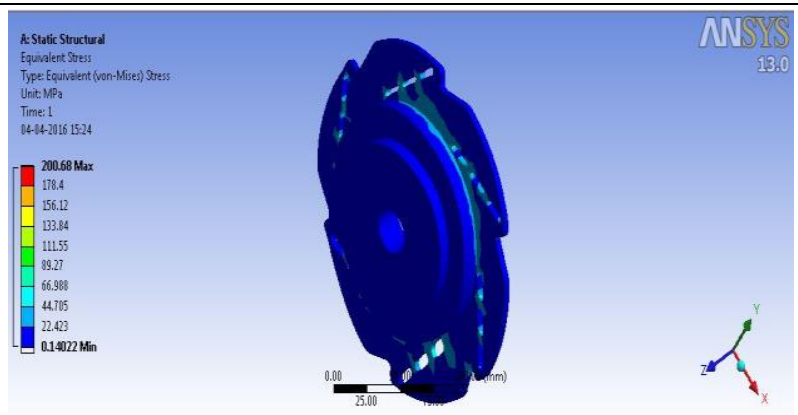

Case 5 : Pedal force $=1500$ N, Pedal ratio=4.5:1, Braking Force=33747.84N; FOS=2.2

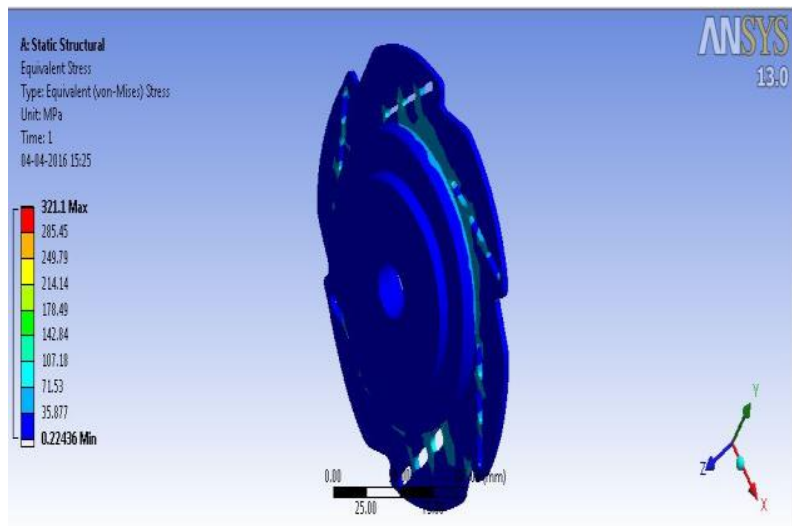

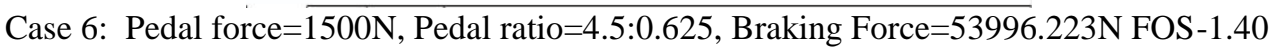

Table 6

Comparing the FOS obtained for different Pedal forces and Pedal Ratios FOS obtained for different cases

\begin{tabular}{lll}
\hline Pedal forces & Pedal ratios & Factor Of Safety (FOS) \\
\hline $1200 \mathrm{~N}$ & 7.2 & 2.1 \\
$1200 \mathrm{~N}$ & 4.5 & 2.8 \\
$1200 \mathrm{~N}$ & 3.6 & 1.75 \\
$1500 \mathrm{~N}$ & 7.2 & 1.68 \\
$1500 \mathrm{~N}$ & 4.5 & 2.2 \\
$1500 \mathrm{~N}$ & 3.6 & 1.40 \\
\hline
\end{tabular}

\section{Conclusion}

The brake disc having a factor of safety (FOS) within the range of 2 to 3 is sustainable. The disc with a FOS less than 2 or greater than 3 undergoes distortion and are less sustainable. Theoretically it has been proven using graphs and calculations that a slight variation in the pedal ratio leads to a large variation in the clamping forces and stopping distance. As per the analysis, factor of safety is the basic criteria that determines the sustainability of the disc. When the structure is said to be steady, the Factor of Safety (FOS) ranges between 2 - 3.As per the comparisons made from the FOS and as per result from Ansys, when the pedal force is $1200 \mathrm{~N}$ and the pedal ratios are 7.2and 4.5, the FOS are 2.1 and 2.8 respectively. Hence the disc is sustainable. When the pedal force is $1500 \mathrm{~N}$, and the pedal ratio is 4.5 , the FOS is 2.2. Hence in this case too, the disc is sustainable. Hence, as the Brake performance is evaluated by the varying pedal ratios and pedal force other than standard ratio a slight variation which resulted in the ratio gives more sustainable results under respective load conditions. As described in the above work a very slight variation in the pedal ratios show a large variation in the braking forces. Therefore by maintaining proper pedal ratios, the length of the pedal can be

Lotte, J. S., Luuk, D. S., Max, S. N., \& Nick, A. S. (2019). The brake pressure depends upon the pedal ratio. International Research Journal of Management, IT and Social Sciences, 6(6), 178-187. https://doi.org/10.21744/irjmis.v6n6.794 
made compact and with effective braking effects. This phenomenon is useful in case of racing vehicles as it reduces the effort of driver. The proper pedal design work also determines the size of master cylinder to be adopted for the vehicle. Depending on pedal ratio the work can be extended for study of pedal travel.

\section{Conflict of interest statement}

The authors declared that they have no competing interests.

\section{Statement of authorship}

The authors have a responsibility for the conception and design of the study. The authors have approved the final article.

\section{Acknowledgments}

The authors would like to thank the editor of IRJMIS for their valuable time, support and advice in completing the current study. 


\section{References}

Barbarisi, O., Palmieri, G., Scala, S., \& Glielmo, L. (2009). LTV-MPC for yaw rate control and side slip control with dynamically constrained differential braking. European Journal of Control, 15(3-4), 468-479. https://doi.org/10.3166/ejc.15.468-479

Bera, T. K., Bhattacharya, K., \& Samantaray, A. K. (2011). Evaluation of antilock braking system with an integrated model of full vehicle system dynamics. Simulation Modelling Practice and Theory, 19(10), 2131-2150. https://doi.org/10.1016/j.simpat.2011.07.002

Chargin, M. L., Dunne, L. W., \& Herting, D. N. (1997). Nonlinear dynamics of brake squeal. Finite Elements in Analysis and Design, 28(1), 69-82. https://doi.org/10.1016/S0168-874X(97)81963-4

El-Tayeb, N. S. M., \& Liew, K. W. (2009). On the dry and wet sliding performance of potentially new frictional brake pad materials for automotive industry. Wear, 266(1-2), 275-287. https://doi.org/10.1016/j.wear.2008.07.003

Eriksson, M., Bergman, F., \& Jacobson, S. (2002). On the nature of tribological contact in automotive brakes. Wear, 252(1-2), 26-36. https://doi.org/10.1016/S0043-1648(01)00849-3

Hui, S., \& Junqing, J. (2010). Research on the system configuration and energy control strategy for parallel hydraulic hybrid loader. Automation in Construction, 19(2), 213-220. https://doi.org/10.1016/j.autcon.2009.10.006

Kamijo, K., Nishihira, Y., Higashiura, T., \& Kuroiwa, K. (2007). The interactive effect of exercise intensity and task difficulty on human cognitive processing. International Journal of Psychophysiology, 65(2), 114-121. https://doi.org/10.1016/j.ijpsycho.2007.04.001

Kim, Y. C., Cho, M. H., Kim, S. J., \& Jang, H. (2008). The effect of phenolic resin, potassium titanate, and CNSL on the tribological properties of brake friction materials. Wear, 264(3-4), 204-210. https://doi.org/10.1016/j.wear.2007.03.004

Kinkaid, N. M., O'Reilly, O. M., \& Papadopoulos, P. (2003). Automotive disc brake squeal. Journal of sound and vibration, 267(1), 105-166. https://doi.org/10.1016/S0022-460X(02)01573-0

Park, E. J., Stoikov, D., da Luz, L. F., \& Suleman, A. (2006). A performance evaluation of an automotive magnetorheological brake design with a sliding mode controller. Mechatronics, 16(7), 405-416. https://doi.org/10.1016/j.mechatronics.2006.03.004

Söderberg, A., \& Andersson, S. (2009). Simulation of wear and contact pressure distribution at the pad-to-rotor interface in a disc brake using general purpose finite element analysis software. Wear, 267(12), $2243-2251$. https://doi.org/10.1016/j.wear.2009.09.004

Tretsiak, D. V., Kliauzovich, S. V., Augsburg, K., Sendler, J., \& Ivanov, V. G. (2008). Research in hydraulic brake components and operational factors influencing the hysteresis losses. Proceedings of the Institution of Mechanical Engineers, Part D: Journal of Automobile Engineering, 222(9), 1633-1645. https://doi.org/10.1243\%2F09544070JAUTO673

Van Winsum, W. (1999). The human element in car following models. Transportation research part F: traffic psychology and behaviour, 2(4), 207-211. https://doi.org/10.1016/S1369-8478(00)00008-5

Lotte, J. S., Luuk, D. S., Max, S. N., \& Nick, A. S. (2019). The brake pressure depends upon the pedal ratio. International Research Journal of Management, IT and Social Sciences, 6(6), 178-187. https://doi.org/10.21744/irjmis.v6n6.794 